\begin{tabular}{lll}
\hline S O B R E & L A T O L E R A N C I A
\end{tabular} 


\section{TOLERANCIA Y PREJUICIO: OBSERVACIONES PARA TOSSA DE MAR}

\section{ARGUMENTO EN FAVOR DE LA TOLERANCIA}

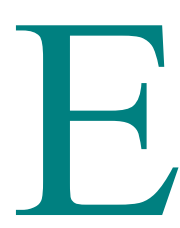

1 argumento en favor de la tolerancia, fundamental para el pensamiento abolicionista, es la elaboración americana del argumento en favor de la tolerancia universal manifestado en variadas formas por Pierre Bayle y John Locke. En Toleration and the Constitution discuto este argumento con alguna extensión haciendo notar que su contexto y sus motivaciones son las de la conciencia moral e intelectual protestante radical que se reflejan en la exigencia política de principio de proteger su proyecto de las opresiones de las iglesias establecidas, tanto católicas como protestantes. Ese proyecto surge tanto de un ideal moral de persona como de la necesidad de proteger ese ideal de una amenaza política que lo había aplastado históricamente. El ideal es el de la persona como detentadora de poder moral para valorar y perseguir racionalmente fines y para ajustar y limitar razonablemente la persecución de sus fines a la luz del igual status moral de las demás personas y del respeto por los iguales derechos que ese status hace surgir. La amenaza política a este ideal de persona es la idea y la práctica política de que los objetivos morales y personales de la gente no son la expresión responsable de sus propios poderes morales, sino que se encuentran especificados, antes de tal reflexión o de la posibilidad de tal reflexión, por una estructura jerárquica de la sociedad y de la naturaleza en las que están inmersos; esa estructura, asociada clásicamente con órdenes del ser, define los roles y status en los que la gente nace, vive y muere y determina exhaustivamente las responsabilidades vitales a la luz de esos roles.

El poder político de la concepción jerárquica se muestra no sólo en los modos en que la gente se comporta, sino en la manera en que penetra 
en el corazón y la mente humana, dibujando una identidad personal, moral y social fundada en los roles especificados por la estructura jerárquica. La estructura -religiosa, económica, política- no necesita alcanzar sus fines mediante la coerción masiva precisamente porque su fuerza de aplastamiento sobre la personalidad humana se ha tornado personal y socialmente invisible para un corazón que no siente y para una mente que no piensa nada que pueda hacer de la estructura un objeto de reflexión crítica; no podría haber nada que pudiera motivar tal reflexión (siendo la vida percibida, sentida y vivida como algo ricamente natural) y mucho menos legitimar su deseabilidad moral. Por supuesto que un orden político tal, siendo humano, hará uso de nuestros poderes racionales cuando los contextos y los roles puedan demandar el ejercicio de la racionalidad práctica (por ejemplo, en la organización de la agricultura o en la guerra), y unas cuantas personas pueden adquirir un nivel de competencia marcadamente alto en el ejercicio de poderes morales críticos (como en las élites ilustradas de las antiguas sociedades jerárquicas, como las de Babilonia, Egipto o los Mayas), pero la vida general de la sociedad no da valor o peso a un ejercicio extensivo de tales poderes.

El poder político de la concepción jerárquica se transforma en el objetivo de la crítica radical cuando, a la luz del pluralismo moral hecho posible por la Reforma, pensadores protestantes liberales como Bayle y Locke articulan un ideal moral de la persona como titular de los poderes morales gemelos de racionalidad y razonabilidad y arguyen que la concepción jerárquica ha subvertido el ideal y, por esa razón, ha distorsionado los criterios de racionalidad y razonabilidad a que el ideal apela. Tanto Bayle como Locke argumentan como cristianos religiosos, y su argumento surge naturalmente como un debate intramuros entre intérpretes de la tradición cristiana, porque una autorizada veta Paulina de esa tradición había dado un peso central al valor de la libertad cristiana y porque esa tradición, como la tradición judía a partir de la que se desarrolla, tiene un poderoso núcleo ético de preocupación por el desarrollo de la personalidad moral (así, la naturaleza trinitaria de Dios, a cuya imagen somos creados, es interpretada por Agustín de Hipona en términos de las tres partes del alma: voluntad, memoria e inteligencia). De hecho, el argumento en favor de la tolerancia surge de una crítica interna de Bayle sobre lo que piensa que es una malinterpretación de Agustín de los valores cristianos centrales de la libre personalidad moral y de la naturaleza de la ética en su argumentación en favor de la persecución de los herejes Donatistas. El asunto, en el fondo, es que la persecución religiosa había corrompido la ética y, por lo mismo, la esencia del elevado y sencillo núcleo ético de hermandad universal de la Cristiandad. 
El nervio del argumento en favor de la tolerancia es que la legitimación de la persecución religiosa tanto por católicos como por protestantes (recabando autoridad de Agustín, entre otros) había hecho de una visión de la verdad religiosa y moral políticamente protegida (entrenched) la medida de lo permisible en ética y religión, incluyendo la indagación y el debate sobre los criterios apropiados en términos de los que la verdad religiosa y moral habían de ser tanto entendidas como valoradas. Sin embargo, a finales del siglo XVII (cuando Locke y Bayle escribían) había llegado a ser plenamente aceptable, e iba a resultar crecientemente claro más tarde, que las visiones de la verdad religiosa y moral políticamente protegidas (que descansaban, por ejemplo, en la autoridad de la Biblia y en una tradición de práctica interpretativa acerca de cómo debía ser entendida) asumían interpretaciones esencialmente controvertibles de una compleja interacción histórica entre las culturas paganas, judía y cristiana de la temprana era Cristiana. El redescubrimiento renacentista de la cultura y enseñanza pagana reabrió la cuestión de cómo había de ser entendida la síntesis cristiana de la cultura filosófica pagana y de la cultura ética y religiosa judía, incluyendo el desarrollo de historiografía crítica y de técnicas de interpretación textual con implicaciones centrales para una razonable interpretación de la Biblia. La Reforma Protestante asumió y estimuló más aún estos nuevos modos de investigación, y también la apelación al experimento y a la experiencia que fueron una matriz para las metodologías asociadas con el auge de la ciencia moderna. Estas nuevas aproximaciones al pensamiento y a la investigación habían puesto plenamente en claro para los más lúcidos pensadores de la época que había una brecha entre las concepciones políticamente atrincheradas de la verdad religiosa y moral (y los modos de investigación asociados a ellas), y los tipos de investigaciones razonables que los nuevos enfoques hacían accesibles. La preocupación que motiva el argumento en favor de la tolerancia es que las concepciones de la verdad políticamente protegidas se habían propuesto a sí mismas, sobre la base de la legitimación de la persecución religiosa, como la medida de los criterios de investigación razonable y de quién podía contar como un investigador razonable de la verdad. Pero a la luz de los nuevos modos de investigación ahora accesibles resultaba cada vez más claro que permitir una protección política tal de la verdad religiosa descansaba no sólo en una degradación de las pautas razonables de investigación, sino en la auto-realizada degradación de la capacidad de las personas para llevar a cabo razonablemente tales investigaciones. Con el fin de atajar estos peligros, el argumento en favor de la tolerancia prohíbe, como cuestión de principio, el forzamiento por el Estado de cualquiera de tales concepciones de la verdad religiosa. El ámbito de la acción política legítima debe descansar, más 
bien, en la persecución de fines generales como la vida y los derechos y libertades (por ejemplo, el derecho a la conciencia), la búsqueda de los cuales es consistente con la gama completa de fines que la gente puede racional y razonablemente perseguir.

Un rasgo prominente de la crítica a la persecución religiosa implícita en el argumento en favor de la tolerancia es la manera en que tal persecución corrompe a la conciencia misma. Tal corrupción, una suerte de ceguera autoinducida hacia los males que uno está infligiendo, es una consecuencia de la amplia imposición política de una concepción de la verdad religiosa que se inmuniza a sí misma de la crítica independiente en términos de criterios razonables de pensamiento y deliberación. En efecto, esa concepción de la verdad religiosa, aunque quizás haya estado en tiempos formada por consideraciones más profundas de razón, cesa de ser mantenida o entendida y elaborada sobre la base de la razón. Una tradición que pierde así el sentido de sus fundamentos razonables se queda estancada y, para mantener la lealtad, cada vez depende más de apelaciones vacías a la ortodoxia de las concepciones de la verdad y de la represión violenta de cualquier disidencia de tales concepciones como una suerte de traición moral desleal. La política de lealtad degenera rápidamente, como lo hizo en la represión sureña de cualquier crítica a la esclavitud anterior a la guerra, en una política irracionalista que se enorgullece de mantener ampliamente valores de la comunidad solamente porque son de la comunidad, y en la que las pautas de discusión e investigación se hacen crecientemente localistas e insulares, aferradas solamente a su polémica función de defensa de los valores existentes en la comunidad y, desde luego, crecientemente hostiles a cualquier valoración razonable más imparcial a la luz de pautas independientes (de ahí, la tendencia a formas de irracionalismo cuando es necesario para proteger su polémico proyecto). De hecho, paradójicamente, cuanto más seriamente vulnerable a la crítica razonable e independiente se hace la tradición, más probable es que genere formas de irracionalismo político orientadas a asegurar la lealtad. Llamaré a este fenómeno de aquí en adelante la paradoja de la intolerancia.

La historia de la persecución religiosa ilustra ampliamente estas verdades, y ningún aspecto de esa historia lo hace más claramente que el antisemitismo cristiano. La relación de la Cristiandad con sus orígenes judíos ha sido siempre tensa y ambivalente ${ }^{1}$. El hecho de

${ }^{1}$ Para un estudio útil del período cristiano temprano, ver Hohn A. Gager The Origins of Anti-Semitism: Attitudes Toward Judaism in Pagan and Christian Antiquity (New York: Oxford University Press, 1983). El Estudio general clásico es Leon Poliakov, The History of Anti-Semitism, vol. 1, trad. Richard Howard (New York: Vanguard Press, 1965); vol. 2, trad. Natalie Gerardi (New York: Vanguard Press, 
que muchos judíos no aceptaran el cristianismo fue una suerte de desafío permanente para la razonabilidad de éste, especialmente en el período temprano (anterior a la adopción del cristianismo como iglesia establecida del imperio romano por Constantino) en el que era una religión proselitista que competía por los creyentes con la amplia gama de sistemas alternativos de creencias religiosas y filosóficas disponibles en el tardío mundo pagano. En sus importantes estudios recientes del anti-semitismo ${ }^{2}$, el medievalista Gavin Langmuir caracteriza como anti-judaísmo las largas tribulaciones del cristianismo con respecto a los judíos por la forma en que el rechazo judío del cristianismo desacreditaba la razonabilidad del sistema de creencias cristiano en el mundo pagano; Langmuir argumenta que la concepción cristiana de la obstinación de los judíos y la concepción de su castigo divino por tal obstinación eran formas naturales de autodefensa antijudaica que desembocaron en las formas de expulsión y segregación de la sociedad cristiana que tales juicios sobre los judíos expresaban y legitimaban naturalmente ${ }^{3}$. En contraste, Langmuir caracteriza como antisemitismo propiamente dicho las creencias irracionales y totalmente carentes de base sobre crucifixiones, rituales y canibalismo de cristianos por judíos que fueron «esparcidas en el norte de Europa alrededor de $1350 »{ }^{4}$; creencias que llevaron a crímenes populares de judíos normalmente (aunque no siempre) condenados tanto por la Iglesia como por las autoridades seculares. Langmuir sugiere, como lo hace R. I. Moore ${ }^{5}$, que el desarrollo del antisemitismo propiamente dicho está asociado con las crecientes dudas internas, en el período de 950-1250, sobre la razonabilidad de ciertas creencias y prácticas religiosas católicas planteadas por disidentes y por las soluciones de tales dudas a través de formas de políticas irracionalistas asociadas con el antisemitismo propiamente dicho. En efecto, los peores estragos del antisemitismo ilustran la paradoja de la intolerancia: precisamente cuando la tradición religiosa dominante suscita las dudas internas más razonables, estas dudas son desplazadas desde la discusión y el debate razonable hacia el irracionalismo político agresivo contra uno de los más visibles, vulnerables e inocentes grupos de disidentes.

1973); vol. 3, trad. Miriam Kochan (New York: Vanguard Press, 1975); vol. 4, trad. George Klin (Oxford University Press, 1985).

${ }^{2}$ Ver Gavin I Langmuir, Toward a Definition of Antisemitism (Berkeley: University of California Press, 1990); History, Religion and Antisemitism (Berkeley: University of California Press, 1990).

${ }^{3}$ Ver págs. 57-62. Langmuir, Toward a Definition of antisemitism.

${ }^{4}$ Pág. 302.

${ }^{5}$ Ver R. I. Moore, The Formation of a Persecuting Society: Power and Deviance in Wester Europe, 950-1250 (Oxford: Basil Blackwell, 1987). 
La distinción de Langmuir entre antijudaísmo y antisemitismo propiamente dicho es inestable. Ambas actitudes descansan en concepciones de la verdad religiosa que son irrazonablemente impuestas por la fuerza a la comunidad; ciertamente, tanto la alegada obstinación de los judíos como su justo castigo por tal obstinación son interpretaciones sectarias de los hechos y no fueron en general impuestas por la fuerza. Las creencias en la obstinación no son desde luego tan irrazonables como las creencias en el canibalismo, y la segregación no es tan mala como el crimen popular o el genocidio, pero ambas formas de política son, sobre la base del argumento en favor de la tolerancia, irracionales como cuestión de principios. Más fundamentalmente: el antijudaísmo puso el fundamento político corrompido al antisemitismo; una vez que resulta políticamente legítimo imponer por la fuerza una concepción sectaria de la verdad religiosa, las dudas razonables sobre tal verdad son desplazadas desde el debate y la discusión razonable que merecen hacia la política irracional de la persecución religiosa, de la cual los judíos han sido las más continuas víctimas visibles en el occidente cristiano, haciendo así del antisemitismo «el más viejo prejuicio de la civilización occidental» ${ }^{2}$.

La radical crítica al irracionalismo político implícita en el argumento en favor de la tolerancia no podía ser, una vez puesta en marcha, limitada a la religión propiamente dicha, sino que fue generalizada con naturalidad por John Locke hasta incluir a la política como tal. La reflexión sobre la injusticia de la persecución religiosa por las iglesias establecidas lleva naturalmente a una reflexión más amplia sobre los modos similares con los que las ortodoxias políticas de los órdenes jerárquicos de autoridad y sometimiento habían sido irrazonablemente impuestos por la fuerza. Tales políticas ilegítimas dieron pábulo a una política irracionalista de glorificación nacional despreocupada de la discusión y el debate razonable sobre la puesta del poder político al servicio de cualquier decente preocupación por los intereses y derechos del pueblo en general; la consecuencia de tal supresión de la argumentación política razonable fue la degradación de la capacidad de las personas para conducir razonablemente tales argumentos en términos de respeto por sus derechos y atención a sus intereses. La generalización del argumento en favor de la tolerancia sugería naturalmente la legitimidad política de algún tipo de democracia constitucional como procedimiento de decisión política más apto para asegurar políticas razonables que respetaran los derechos humanos y persiguieran los intereses comunes de todas las personas por igual.

${ }^{2}$ Pág. 45. Langmuir, Toward a Definition of Antisemitism. 
El argumento en favor de la tolerancia está motivado por un escepticismo político general sobre la razón en la política, en particular en la política que imponía, en general por la fuerza, concepciones sectarias de la verdad religiosa, moral y política. Para los principales filósofos de la tolerancia era perfectamente natural, a la luz de esta preocupación, tratar de articular algunos criterios o pautas experimentales en términos de los que tales puntos de vista sectarios pudieran ser valorados y desmontados desde una perspectiva más imparcial. Así Bayle arguye:

«... como quiera que las pasiones y los prejuicios oscurecen con demasiada frecuencia las ideas de la equidad natural, aconsejaría a una persona que pretenda conocerlas bien que considerase estas ideas en general y abstraídas de todo interés privado y de las costumbres de su país. Puede suceder que una pasión fervorosa y profundamente arraigada persuada a un hombre de que una acción que él contempla como beneficiosa y placentera para sí es consonante con los dictados de la recta razón. Puede suceder que la fuerza de la costumbre y la disposición dada al alma durante la instrucción en la primera infancia puedan producir que se encuentre honestidad donde no la hay. Para superar ambos obstáculos, por tanto, me gustaría que quienquiera que pretenda conocer claramente esta luz por encima de su propio interés privado o de la costumbre de su país, se pregunte a sí mismo en general: «¿Es tal práctica justa en sí misma? Si se suscitara la cuestión de introducirla en un país donde no estuviera en uso y en donde se fuera libre de aceptarla o no aceptarla ipensaría uno, tras examinarla imparcialmente, que es lo bastante razonable como para merecer ser adoptada?» ${ }^{3} \quad$ El uso por Bayle de un criterio contractualista es, como es sabido, generalizado por Locke en una teoría política contractualista comprensiva, como demuestro en Foundations of American Constitutionalism. Aunque Locke no es claro en este punto, el contractualismo no tiene nada que ver con la historia; nada en la argumentación gira en torno a la existencia real de un estado de naturaleza. Más bien, como Jeffrey Reiman ha expuesto contundentemente, en el contractualismo «el estado de naturaleza es el equivalente moral de la duda cartesiana $\rangle^{4}$. Descartes no era, por supuesto, un escéptico epistemológico radical, sino más bien un filósofo del conocimiento preocupado por el modo poco fiable en el que las creencias eran convencionalmente formadas;

${ }^{3}$ Pág. 30. Pierre Bayle, Philosophical Commentary, Amie Godman Tannenbaun(trad.) (New York: Peter Lang, 1987).

${ }^{4}$ Pág. 69. Jeffrey Reiman. Justice and Modern Moral Philosophy. (New Haven: Yale University Press, 1990). 
por esta razón estaba ocupado heurísticamente en descubrir qué podría contar como base razonable sobre la que pudieran formarse creencias fiables, y la duda cartesiana fue un modo de articular lo que él pensaba que debía ser esa base. Del mismo modo ni Bayle ni Locke eran escépticos morales, políticos o religiosos; más bien estaban preocupados por las dudosas apelaciones a las concepciones, impuestas políticamente por la fuerza, de las verdades sectarias, y buscaban una vía de articulación de un experimento teórico de razonabilidad contractualista abstracta como método de valoración de lo que podía ser legítimamente impuesto por la ley. El uso por Bayle de un criterio contractualista plantea esto exactamente: Haciendo abstracción de tus propios objetivos y de las costumbres particulares de tu sociedad ¿qué principios de política legítima aceptarían razonablemente todas las personas? El test es, desde luego, muy parecido al criterio contractualista abstracto de la ausencia de conocimiento de la identidad específica de Rawls, y cumple exactamente la misma función política.

Es fundamental para una evaluación como esa que se entienda que las personas tienen los poderes morales idénticos de racionalidad y razonabilidad a la luz de los que pueden ponderar los fines humanos, tanto propios como de otros ${ }^{5}$. Los principios de la prudencia nos capacitan para reflexionar sobre la coherencia y complementariedad entre nuestros fines y los modos más efectivos de perseguirlos según principios de racionalidad epistémica; y los principios de razonabilidad moral nos capacitan para regular la persecución de nuestros fines a la luz de las demandas comunes de todas las personas a formas de acción y omisión consistentes con un igual respecto para nuestro status en la comunidad moral. Estos auto-originados poderes de la razón nos capacitan no sólo para pensar por nosotros mismos desde nuestro propio punto de vista sino también para pensar desde el punto de vista de cualquier otro. La razón puede tener el poder que tiene en nuestras vidas porque nos capacita para distanciarnos de nuestros fines, para valorar críticamente cómo encajan entre sí y con los fines de otros y para reexaminar y a menudo revisar tales juicios a la luz de nuevas informaciones y experiencias y actuar de acuerdo con ello. La razón sólo puede cumplir fiablemente este papel cuando ella misma está abierta a revisión y corrección a la luz de cánones públicos abiertos y accesibles a todos; puesto que la razón, siendo como es un recurso que capacita a todas las personas para cultivar mejor sus poderes morales, exige una cultura pública que mantenga altos estándares de argumentación independiente,

${ }^{5}$ Para una descripción más completa de estos poderes, ver David A. J. Richards, A Theory of Reasons for Action (Oxford: Clarendon Press, 1971). 
críticamente revisable y accesible a todos. Para cumplir el papel que puede jugar en el autogobierno de nuestras vidas, la razón no puede ser usada unilateralmente, sino que debe suministrarnos un espacio suficiente en el que podamos expresar cómodamente qué dudas podemos o debemos tener sobre nuestros fines, y discutir y resolver tales dudas ${ }^{6}$.

La pretensión de que esta concepción descansa en una visión metafísica falsa y superficial de un agente sin fines profundos ${ }^{7}$ no acierta a tomar en serio la consideración de nuestra libertad moral que ofrece. Nada en esa concepción niega los obvios hechos sociales de nuestra crianza, nuestra socialización y las comunidades con las que nos identificamos profundamente; y esa concepción lleva implícita una profunda comprensión de la personalidad humana y de nuestros fines y las maneras en las que nuestros poderes morales prosperan sólo a través del lenguaje y la cultura pública que dan expresión a la vida de la razón. Nuestra libertad moral, en la medida en que la tenemos y la cultivamos, no es una libertad anómica de rechazar o adoptar fines arbitrariamente, sino la libertad de ejercitar nuestros poderes morales apelando a la razón con todo lo que eso implica de perspectiva e imparcialidad sobre nuestros fines ${ }^{8}$.

Así entendida, nuestra capacidad para razonar exige, como he sugerido, una política que respete el principio de tolerancia. Tal principio niega que las convicciones de la verdad sectaria puedan ser forzadas mediante el derecho (el papel de tales convicciones en la vida privada es, por supuesto, otra cuestión), y, en esa medida, limita la fuerza en la vida política de convicciones que sólo obtienen su fuerza de las certezas de la lealtad e identificación de grupo, las cuales, de acuerdo con la paradoja de la intolerancia, tienden crecientemente a auto-aislarse a sí mismas de la razón cuando están más razonablemente sometidas a dudas internas. Nada en esta perspectiva sugiere que los puntos de vista religiosos o incluso las convicciones acerca de la verdad de las religiones dominantes sean o no razonables, sino solamente que ciertos hechos de psicología política acerca de la naturaleza humana llevan a una suerte de corrupción política de los proyectos religiosos como indagaciones sobre la verdad última; el ejercicio del poder político forzando las visiones de la verdad religiosa tiende a no hacer

${ }^{6}$ Para una útil discusión de todos estos puntos, ver Onora O'Neill Constructions of Reason (Cambridge: Cambridge University Press, 1989).

${ }^{7}$ Ver Michael J. Sandel, Liberalism and the Limits of Justice (Cambridge: Cambridge University Press, 1982). 1990).

${ }^{8}$ Ver, en general, Susan Wolf, Freedom Within Reason (New York: Oxford University Press, 
eso sobre la base de la razón. Desde luego, de acuerdo con la paradoja de la intolerancia, precisamente cuando la tradición más pueda necesitar mantener, discutir y resolver dudas razonables sobre su verdad, más tiende a combatir las dudas razonables mediante esas formas despreciables de irracionalismo político ejemplificadas por la historia de la persecución religiosa.

El contractualismo, entendido como un test hipotético hacia la razón en política, debe tender, por la propia naturaleza de su proyecto, a identificar los rasgos más abstractos que caracterizan nuestras facultades morales como agentes raciocinantes. Como la motivación de todo el proyecto es estudiar el grado hasta el que la idea y la práctica de los órdenes jerárquicos de autoridad se ha permitido subvertir nuestros poderes morales de racionalidad y razonabilidad, la reclamación de tales poderes requiere un test exigente de legitimidad política que constriña y limite al poder político, puesto que, a la luz de nuestra experiencia histórica, tenemos buenas razones para creer que requiere limitación para hacer justicia a las demandas razonables de nuestra naturaleza moral. El contractualismo nos ofrece tal test, pidiéndonos que haciendo abstracción de nuestros fines y situaciones particulares cotidianas, pensemos hipotéticamente sobre los rasgos más generales de una vida racional y razonable y sobre qué constricciones sobre la política se requieren para que a todas las personas les sea asegurado el vivir esa vida. Las ideas de bienes o recursos o capacidades generales -tan familiares en la literatura contractualista- son corolarios de dicho test; identifican el tipo de rasgos abstractos de vida que personas razonables, en la situación de elección contractualista, contemplarían como adecuadamente regulados por el principio distributivo de una política justa. El principio de tolerancia es un principio de este tipo, dado que se ocupa de los principios fundacionales que hacen posible tanto una política de razón como una concepción de la comunidad política que dignifica la capacidad de todas las personas para ser agentes morales razonables que se autogobiernan.

\section{TEORÍA DEL RACISMO}

La percepción crítica plenamente moderna de los abolicionistas sobre las raíces culturales del racismo (su confusión esencial de la cultura con la naturaleza) ${ }^{9}$ se hallaba conectada íntegramente en el núcleo de su crítica a la esclavitud con el argumento en favor de la

${ }^{9}$ Ver, por ejemplo, pág. 11, Pierre L. van den Berghe, Race and Racism (New York; John Wiley \& Sons, 1967). 
tolerancia. Los abolicionistas estaban comprometidos con el derecho de la conciencia moral del Protestante radical, y pusieron en el centro de su crítica de la esclavitud el modo en que ésta dependía de la disminución de la conciencia tanto de los esclavos como de cualquiera que criticara la institución. Ellos comprendieron, como no lo hicieron otros americanos de su generación, la medida en la que la legitimación política de la esclavitud en la América protestante dependía de la asunción de que los negros eran, funcionalmente, el equivalente de lo que la intolerancia agustiniana llamaba herejes culpablemente ciegos. La penetrante visión abolicionista captó una importante verdad sobre los orígenes de la esclavitud en la América colonial, la manera como había sido justificada sobre la base de que los negros eran paganos no-cristianos ${ }^{10}$ y el modo en el que esa suposición había sido auto-legitimada por la suposición racista de que los negros carecían de tal modo de capacidad moral que eran como paganos permanentes. El análisis abolicionista del racismo era un análisis cultural de cómo la naturaleza particularmente onerosa de la esclavitud americana (prohibiciones de leer $\mathrm{y}$ escribir, de organización religiosa y de matrimonio, y limitaciones y eventuales prohibiciones de manumisión $)^{11}$ y las formas asociadas de discriminación racial contra los negros libres del norte habían producido socialmente la imagen de incapacidad negra que justificaba ostensiblemente su status permanente de paganos (fuera de la comunidad capaz de libertad moral cristiana). Para los abolicionistas, coherentemente con el argumento en favor de la tolerancia, la esclavitud y la discriminación eran formas de persecución religiosa, social, económica y política motivadas por una concepción políticamente protegida de la incapacidad negra que imponía su propia concepción de la verdad tanto contra criterios de investigación razonable como contra las capacidades de razonabilidad de negros y blancos que pudieran desafiar esa concepción. Una concepción de la unidad política, sujeta a dudas razonables

${ }^{10}$ Ver págs. 56, 65, 91-98, Winthrop D. Jordan, White over Black: American Attitudes toward the Negro, 1550-1812 (New York: W. W. Norton, 1977); págs. 328-32, Edmund S. Morgan, American Slavery American Freedom (New York, W. W. Norton, 1975).

${ }^{11}$ Sobre los rasgos especiales de la esclavitud americana, en contraste con cualquier otra, ver Stanley M. Elkins, Slavery, 3. a ed. revisada (Chicago: University of Chicago Press, 1976); Kenneth M. Stampp, The Peculiar Institution (New York: Vintage, 1956); Eugene D. Genovese, The World the Slaveholders Made (Middletown, Conn.: Wesleyan University Press, 1988); John W. Blassingame, The Slave Community, 2. ${ }^{\text {a }}$ ed. (New York: Oxford University Press, 1979); Carl N. Degler, Neither Black nor White (Madison, Wis.: University of Wisconsin Press, 1986); Peter Kolchin, Unfree Labor: American Slavery and Russian Serfdom (Cambridge, Mass.: Harvard University Press, 1987). 
acerca de su fundamento y méritos, había resuelto irrazonablemente sus dudas mediante las certidumbres irracionales y racistas de la solidaridad grupal sobre la base de una injusta subyugación de grupo. Frederick Douglass, el líder abolicionista negro, lo planteó enérgicamente:

«La ignorancia y la depravación, la incapacidad para elevarse desde la degradación a la civilización y la respetabilidad, son las alegaciones más usuales contra los oprimidos. Los males más fomentados por la esclavitud y la opresión son precisamente aquellos que los esclavistas y los opresores trasladan desde su sistema al carácter inherente de sus víctimas. Así los propios crímenes de la esclavitud se transforman en la mejor defensa de la esclavitud. Haciendo del esclavizado un carácter sólo idóneo para la esclavitud se excusan a sí mismos por rehusarse a hacer del esclavo un hombre libre» ${ }^{12} \quad$ Los abolicionistas estaban, desde luego, familiarizados con los previos argumentos de la naciente «ciencia» americana de la etnología que apelaba a presuntas diferencias físicas entre el tamaño del cerebro, etc... entre negros y blancos para argüir en favor de diferencias en su capacidad ${ }^{13}$. La Etnología apelaba al respeto protestante por la experiencia y el método científico, y como es natural, era cultivada y usada intensamente por los sureños para sugerir que las suposiciones racistas no eran irrazonables tal y como lo habían sugerido los abolicionistas ${ }^{14}$. Pero, incluso en el relativamente incoherente estado de las ciencias humanas en este período, abolicionistas como James Russell Lowell ${ }^{15}$, Frederick Douglass ${ }^{16}$, y Charles Sumner ${ }^{17}$, cuestionaron tanto la validez del enfoque general, su interpretación de los datos y su ignorancia de otras evidencias, como el que dejaran de tomar en serio las ideas morales ${ }^{18}$ y la importancia de la cultura para las ciencias humanas ${ }^{19}$. Para los abolicionistas la ética era, como hemos visto, una apelación íntima a un igual respeto abstracto por los poderes morales de todas las

${ }^{12}$ Pág. 295, «The Claims of the Negro Ethnologically Considered», en Philip S. Foner, ed. The life and Writings of Frederick Douglass, vol. 2 (New York: International Publishers, 1975).

${ }^{13}$ Para un buen estudio general, ver William Stanton, The Leopard's Spots: Scientific Attitudes Toward Race in America 1815-59 (Chicago: University of Chicago Press, 1960).

${ }^{14}$ Ibídem.

${ }^{15}$ Ver «Ethnology», págs. 26-32, vol. 11, Anti-Slavery Papers of James Russell LoweIl.

${ }^{16}$ Ver ob. cit. en nota 16, págs. 289-309.

${ }^{17}$ Ver «The Question of Caste», págs. 131-183, Charles Sumner: His Complete Works, vol. XVII (New York: Negro Universities Press, 1969).

${ }^{18}$ Ver Douglas, op. cit., págs. 292, 307-08; Sumner, op. cit., págs. 138-9.

${ }^{19}$ Ver, especialmente, Douglas, op. cit., págs. 304-06. 
personas, y su interpretación de este ideal moral a la luz del argumento en favor de la tolerancia les llevó a ser los únicos en su generación que sospecharon y cuestionaron negaciones de la capacidad moral como esas de los etnólogos que tan irrazonablemente confundían los resultados de una cultura corrompida con la naturaleza ${ }^{20}$.

El argumento anti-racista abolicionista sobre la falta de razonabilidad de la exclusión de los negros de la comunidad política americana fue planteado con frecuencia de un modo que lo conectaba directamente con la teoría política lockeana del constitucionalismo americano. Theodore Weld señaló esto tan convincentemente como nadie en su American Slavery as It is: el objetivo lockeano de una sociedad política legítima es la mejor protección de los derechos naturales iguales de todos y coherentemente la justa distribución de los beneficios y cargas de la vida política; pero los negros, que han sido excluidos sin razón de la comunidad política americana, han soportado grandes cargas de contribución a la vida americana, pero no han recibido el correspondiente respeto por sus derechos o atención a sus intereses; la justicia exige que les sea acordada una igual protección de sus derechos por la ley $^{21}$. La inclusión de los negros en la comunidad política americana es una exigencia mínima de los principios básicos de legitimidad política de la sociedad.

Una indicación asombrosa de la revolución moral en la opinión pública americana operada por la guerra civil es que los argumentos de los abolicionistas, contemplados como marginales y radicales en el período anterior a la guerra, articularon los principios básicos que el Congreso de Reconstrucción incorporó a las enmiendas de Reconstrucción. El fuerte contraste entre la contribución negra a la guerra civil y los intentos intransigentes del Sur de devolver a los liberados al equivalente funcional de la esclavitud permitieron que el liderazgo del Partido Republicano en el Congreso forjara una opinión pública en la nación -a despecho de un presidente que se resistía- que mantenía los principios centrales de las enmiendas de Reconstrucción: una ciudadanía nacional de iguales derechos se extendía a todos los americanos nacidos en los Estados Unidos (anulando Dred Scott), los derechos humanos básicos se extendían a todos los ciudadanos y tales derechos eran objeto de un apoyo nacional frente a los estados, a todas las personas se les garantizaba igual protección e iguales derechos políticos eran extendidos a los americanos negros. En efecto, los negros americanos

${ }^{20}$ Para el desarrollo posterior de esta visión en la teoría social americana, ver Carl N. Degler, In Search of Human Natura (New York: Oxford University Press, 1991).

${ }^{21}$ Ver págs. 150-15 1. 
son incluidos en la comunidad política americana sobre la base de principios que les garantizan la igual protección de sus derechos humanos básicos. La visión abolicionista de la igualdad de derechos había sido hecha realidad.

Por supuesto que no se hizo realidad. Un Presidente de la exquisita destreza política y moralidad de principios de un Lincoln podría haber tenido alguna oportunidad de llevar a la nación (Norte y Sur) a algún consenso duradero de principio sobre el respeto a los derechos constitucionales de los negros americanos ${ }^{22}$, pero Andrew Johnson carecía tanto de destreza como de principios, y polarizó tanto a la nación que «el Sur se unió (en el racismo) como no había estado unido en la esclavitud» ${ }^{23}$. Los principios de las Enmiendas de Reconstrucción sólo podrían, en tales circunstancias, haber sido impuestos por un compromiso permanente del Norte con el continuo reforzamiento federal de los derechos constitucionales en el sur, pero el compromiso cesó en $1877^{24}$. El poder judicial federal amputó virtualmente algunos de los principios centrales de las Enmiendas de Reconstrucción (especialmente con su estrecha construcción de la cláusula de Privilegios e Inmunidades de la Enmienda Decimocuarta y de la acción del estado bajo la cláusula de Igual Protección de esa enmienda), y en Plesssy versus Ferguson ${ }^{25}$, bajo la influencia de la ciencia social racista dominante en los últimos años del siglo XIX, se abandonó la interpretación abolicionista antirracista de la cláusula de Igual Protección. La consecuencia fue, en el Sur Americano, una cultura política en la que una ideología racista de supremacía blanca se atrincheró a sí misma en el poder político excluyendo a los negros americanos de la política (en clara violación de la Enmienda Decimoquinta), y, mediante la segregación, excluyéndoles del igual respeto por sus derechos por parte de los estados. La identidad política del Sur como comunidad se inmunizó a sí misma irrazonablemente frente a la discusión rigurosa de su mayor perversión ${ }^{26}$; y coherentemente con la paradoja de la intolerancia, tal fracaso de la razón se alimentó ulteriormente en el irracionalismo político de la subyugación racista de sus víctimas. Las consecuencias

1985).

${ }^{22}$ Ver La Wanda Cox, Lincoln and Black Freedom (Urbana: University of Illinois Press,

${ }^{23}$ Pág. 166, C. Vann Woodward, «Emancipations and Reconstructions: A Comparative Stydy», op. cit.

${ }^{24}$ Ver C. Vann Woodward, Reunion and Reaction: The Compromise of 1877 and the End of Reconstruction (New York: Oxford University Press, 1966).

${ }^{25}$ Ver Charles A. Lofgren, The Plessy Case (New York: Oxford University Press, 1987).

${ }^{26}$ Ver W. J. Cash, The Mind of the South (New York: Vintage Books, 1941). 
para la nación en sentido amplio se dejaron sentir no sólo en los aspectos racistas de la política exterior americana, sino también en las restricciones racistas a la inmigración de asiáticos $\mathrm{y}$, tras la primera guerra mundial, de europeos del sur y del este. Si en este período la raza y la cultura estuvieron tan irrazonablemente confundidas, no es sorprendente que la intolerancia americana, en la medida permitida por la traición a los principios constitucionales, habría de volverse de los negros a los asiáticos no cristianos, a los católicos latinos o los judíos eslavos, cuyas culturas aparecían, a los ojos de la opinión pública nativista americana y protestante, tan inferiores y (equiparando cultura y raza), por eso mismo, pobladas por gentes racialmente inferiores. Pero volvamos la vista, como es natural, a esos fenómenos europeos comparables que la erosión americana de sus ideales constitucionales durante este período tan claramente reflejó y de los que en alguna medida tomó inspiración.

Si la política americana está durante este período preocupada por la cuestión de incorporar a los esclavos negros emancipados a la comunidad política, la cuestión política comparable con ella en Europa está enmarcada por la emancipación de los judíos, poderosamente impulsada por los principios del pensamiento ilustrado incorporados a la Revolución Francesa ${ }^{27}$ frente al trasfondo del viejo antijudaísmo y antisemitismo que antes discutimos. En el período medieval, tanto la expulsión de los judíos como su segregación fueron justificadas sobre la base de que eran, legítimamente, los siervos o esclavos de los príncipes cristianos a causa de su negativa culpable a adoptar las creencias cristianas ${ }^{28}$; indudablemente la segregación de las comunidades judías de la vida, ocupaciones y responsabilidades de las comunidades cristianas -operada, como lo era, para estigmatizar su culpabilidad- creó una imagen cristiana de la cultura judía como cultura inferior, el tipo de degradación cultural que formó, como hemos visto en el caso de los negros americanos, el contexto del racismo americano. Como veremos ahora, también era parte del trasfondo histórico de la moderna forma europea de racismo que llamamos antisemitismo.

El moderno antisemitismo europeo, llamado algunas veces por sus estudiosos antisemitismo anticristiano ${ }^{29}$, surge en el contexto de la tensa relación entre los emergentes principios europeos de los derechos humanos universales, patrocinados por la Revolución Francesa, y las luchas del siglo XIX por un sentido de identidad y autodeterminación

${ }^{27}$ Ver Arthur Hertzberg, The French Enlightenment and the Jews (New York: Columbia University Press, 1990).

${ }^{28}$ Ver págs. 156-7. Langmuir, Toward a Definition of Antisemitism.

${ }^{29}$ Ver, en general, Uriel Tal, Chistians and Jews in Germany, Noah Jonathan Jacob (trad.) (Ithaca; Cornell University Press, 1975). 
nacional; cuando la Revolución Francesa tomó la forma de revolución mundial napoleónica, esas fuerzas se hicieron fatalmente contradictorias. La emancipación de los judíos tuvo lugar fatalmente en este tenso ambiente y devino, con el tiempo, su más terrible víctima. Los judíos, cuya emancipación fue patrocinada por la apelación a derechos humanos universales, fueron identificados con una cultura hostil a la emergencia de la auto-determinación nacional. Sus mismos intentos de asimilación a esta cultura eran, desde esta perspectiva, signos de su degradada incapacidad para la verdadera cultura nacional.

Las luchas por la identidad nacional en la Europa del siglo XIX -contra, por ejemplo, el trasfondo de las balkanizadas principalidades alemanas, los reinos italianos y la dominación imperialista por no-alemanes y no-italianos- no eran, por supuesto, luchas religiosas; de hecho muchas de ellas eran conscientemente seculares en su naturaleza y algunas profundamente antirreligiosas (así, el antisemitismo anticristiano alemán). La religión no era de ordinario la voz de llamamiento de la identidad nacional, pero sí lo era la cultura -la cultura entendida a menudo en términos de unidad lingüística como base de una más grande y última unidad nacional (así, en el pangermanismo). La unidad nacional, particularmente en Alemania, fue progresivamente identificada con la forja de una ortodoxia cultural centrada en la pureza de la lengua alemana, sus viejos mitos «arios» $»^{30}$, su alta cultura. La unidad cultural no es, por definición, una base ilegítima para la unidad nacional; una cultura política comprometida con el pluralismo y los derechos humanos universales puede, por ejemplo, ser legítima, incluso altamente deseable y éticamente valiosa. Pero la búsqueda de la unidad cultural en Europa había surgido en parte como reacción a la interpretación francesa imperialista y asimilacionista de los derechos humanos universales, y esa historia invitaba a la búsqueda de un concepto alternativo, lingüística y culturalmente orientado, de la unidad nacional. Pero la unidad cultural -cuando es expresamente hostil a los derechos humanos universales así como a tradiciones religiosas universalistas (considérese el impacto de Nietsche, cualquiera que fueran sus intenciones) asociadas con el mantenimiento de un compromiso público con los derechos humanos- es una base inestable, altamente infundada y éticamente regresiva, para la unidad nacional. De hecho, puede articular y afirmar sus valores positivos -a veces muy escasamente razonables- sólo por la fuerza de una reacción mortífera contra sus imaginarios enemigos espirituales; y es del todo cómodo históricamente identificar

${ }^{30}$ Para un soberbio tratamiento, ver Leon Poliakov, The Aryan Myth: A History of Racist and Nationalist Ideas in Europe. Edmund Howard trad. (London: Sussex University Press, 1971). 
esos enemigos con los judíos, una minoría cultural altamente vulnerable e históricamente estigmatizada: algo así como, el caso paradigmático de herejía cultural. En el caso alemán, en el que había poco trasfondo histórico sólido y humano de unidad nacional sobre el que construir (la Italia de Mussolini, en contraste, tenía la historia de la tolerancia pluralista romana de los judíos para inspirarse en la censura del verdadero antisemitismo alemán de Hitler) ${ }^{31}$, los valores estéticos románticos dominaron progresivamente sobre los valores éticos. Richard Wagner, una influencia grande en el desarrollo del antisemitismo alemán, consideraba así, absurdamente, su genio artístico (difícilmente, en su caso, confundible con su sentido moral) como algo suficiente para autorizarlo a articular, como un líder moral profético tipo Lincoln, una visión ética para el pueblo alemán en el mito ario incorporado en Parsifal, una sorprendente confusión de las categorías del liderazgo estético y ético que refleja la crisis subyacente en la cultura ética y política ${ }^{32}$. Hitler iba, por supuesto, a pretender que la espada del fascismo había sido forjada en Bayreuth.

Estas fatales confusiones son brillantemente diseminadas en el inmensamente influyente libro de Houston Chamberlain The Foundations of the Nineteenth Century ${ }^{33}$, una obra muy admirada por Hitler. Chamberlain, yerno de Wagner, ofrece una historia cultural del mundo en la que la cultura aria es el depósito y vehículo de todo valor y los judíos, como racionalistas carentes de imaginación creativa, la personificación del valor negativo. En efecto, Chamberlain hace una llamada a una ortodoxia cultural impuesta políticamente y que se centra en la cultura aria contra la corruptora cultura no-aria (judía). El argumento de Chamberlain ejemplifica claramente la paradoja de la intolerancia: admite que hay razonables dudas científicas sobre la equiparación de lenguaje y raza (que subyace a su tesis), pero resuelve esas dudas mediante una apelación a una certidumbre expresiva del irracionalismo político de la voluntad:

«Aunque fuera probado que nunca hubo una raza aria en el pasado, deseamos sin embargo que en el futuro pueda haber una. Este es el decisivo punto de vista para la acción de los hombres» ${ }^{34}$.

${ }^{31}$ Ver pág. 70. Poliakov, The Aryan Myth.

${ }^{32}$ Ver Leon Poliakov, The Aryan Myth; The History of Antisemitism, vol. III, cap. 11. Sobre el conjunto de creencias realmente confuso de Wagner, ver Jacob Katz, The Darker Side of Genius (Honover: University Press of New England, 1986).

${ }^{33}$ Houston Stewart Chamberlain, The Foundations of the Nineteenth Century, trad. de John Lees (London: John Lane, 1911) 2 vols.

${ }^{34}$ Pág. 266, n., ibid., vol. I. 
Jesús de Nazaret, a quien Chamberlain pretende admirar mucho, debe ser, por supuesto, un no-judío, un ario de hecho. Estamos en el país de la ilusión donde los deseos se hacen mágicamente realidad.

Es un síntoma del papel progresivamente dominante del irracionalismo político en el racismo moderno el que Chamberlain deba dar una interpretación racial de un argumento esencialmente cultural precisamente en un momento en el que tales puntos de vista, como él reconoce, estaban bajo examen y crítica entre los estudiosos del lenguaje o, más generalmente, de la cultura. Franz Boas, un antropólogo y judío alemán que emigró a Estados Unidos, donde se transformó en un arquitecto central de las modernas ciencias humanas de la cultura, había empezado a desenmascarar seriamente las suposiciones raciales de la antropología europea y americana tan temprano como en $1890^{35}$. De un modo que no había sucedido cuando los etnólogos americanos escribían, la teoría racial estaba ahora bajo un duro ataque como científicamente infundada. Pues bien, es en este preciso contexto en el que al creciente irracionalismo del pensamiento racial le fue dada su más amplia y peligrosa expresión política en la legitimación de la forja de una nueva concepción de la base de la unidad e identidad política.

Las consecuencias malignas de la dinámica de tal irracionalismo cuando es real y seriamente uncido a un poder político agresivamente hostil a los derechos humanos, se desplegaron completamente en la historia del moderno antisemitismo político ${ }^{36}$. Los líderes políticos obtienen o mantienen apoyo político populista para gobiernos que violan los derechos humanos y cuya legitimidad está, por ello, en duda, mediante la apelación a temores racistas como base de la unidad nacional, incluyendo la patente distorsión y falsificación de hechos que, de acuerdo con Chamberlain, inspiran la voluntad nacional con irrazonable certidumbre (por ejemplo, el asunto Dreyfus en Francia, y los Protocolos de los Sabios de Sión en la Rusia Imperial) ${ }^{37}$. En el mundo alemán el antisemitismo político se transforma, como Hitler vio y

${ }^{35}$ Ver Franz Boas, «Human Faculty as Determined by Race», págs. 221- 42, en George W. Stocking Jr. ed. A Franz Boas Reader (Chicago: University of Chicago Press, 1974), publicado originalmente en American Association for the Advencemente of Science, Proceedings 43 (1894): 301-27. Para una expresión más completa de los puntos de vista de Boas, ver Franz Boas, The Mind of Primitive Man (Westport, Conn.: Greenwood Press, 1963) (1. ${ }^{\mathrm{a}}$ ed. publicada, 1911). Sobre la influencia crítica de Boas sobre la moderna teoría social, ver George W. Stocking, Race, Culture and Evolution (New York: The Free Press, 1968) Carl J. Degler, In Search of Human Nature (New York: Oxford University Press, 1991).

${ }^{36}$ Ver, en general, el magistral trabajo de Leon Poliakov, The History of Anti-Semitism, 4 vols.

\footnotetext{
${ }^{37}$ Ver, Leon Poliakov, The History of Anti-Semitism, vol. IV.
} 
comprendió claramente, en el núcleo mismo del éxito de la política nazi en una nación humillada por las triunfantes democracias en la Primera Guerra Mundial ${ }^{38}$, y los criterios razonables de discusión y debate sobre temas de raza y derechos humanos son brutalmente suprimidos en virtud de una pseudociencia de la raza promocionada por el gobierno e impuesta por el terror totalitario ${ }^{39}$. El Nazismo, por supuesto, estaba conscientemente en guerra con la idea y la práctica de los derechos humanos, incluidas las instituciones del gobierno constitucional basadas en la construcción de una política de raciocinio público que respetase los derechos humanos ${ }^{40}$. Su política de solidaridad grupal artificialmente construida sobre el mito, el ritual y la pseudociencia, al carecer en absoluto de base en la razón pública, se vio empujada, por la dinámica interna de la paradoja de la intolerancia, a manufacturar una base de unidad en una irracionalista voluntad de creer en los fantasmagóricos males degradados de los judíos. La construcción social del racismo es llevada en la política Nazi a sus extremos más irracionalistas e inmorales porque la base de la unidad de la política Nazi es una solidaridad social de sinrazón política.

\section{CONCLUSIONES}

La preocupación moderna por la idea y la práctica política de los derechos humanos hizo surgir el argumento en favor de la tolerancia en base al cual sus principales defensores razonaron en favor y pusieron en práctica la tolerancia universal (la emancipación de los judíos) y la abolición de la esclavitud (la emancipación de los negros). El mal político del racismo moderno debe ser entendido como una reacción a las demandas de tolerancia y derechos humanos, en particular como una reacción a la inclusión de grupos cuyos derechos habían sido injustamente denegados. Las diferencias culturales (en la medida que existen) de aquellos grupos respecto de la dominante ortodoxia cultural, que son con frecuencia el producto de una historia de subyugación, son hipostasiadas proyectivamente en unas diferencias raciales naturales que son la base para los intentos de excluirlos de la comunidad política, llegando en el peor extremo al genocidio. Tanto el racismo americano como el moderno antisemitismo europeo son violaciones centrales de

${ }^{38}$ Ver Peter Pulzer, The Rise of Political Anti-Semitism in Germany and Austria, rev. ed. (Cambridge, Mass.: Harvard University Press, 1988); Jacob Katz, From Prejudice to Destruction (Cambridge, Mass.: Harvard University Press, 1980).

${ }^{39}$ Ver, en general, Hannah Arendt, The Originds of Totalitarianism (New York: Harcourt Brace Jovanovich, 1973).

${ }^{40}$ Ver Hannah Arendt, nota anterior. 
la exigencia de igual protección que se debe a todas las personas sometidas al poder político legítimo; igual protección de sus derechos inalienables y cuidado imparcial de sus intereses. Ambos son intentos injustos de excluir a ciertos grupos del alcance de esa exigencia a través de una quiebra de la razón pública que ha sido puesta en claro por la importancia seminal del argumento en favor de la tolerancia en el moderno constitucionalismo. El moderno racismo de Europa y América está enraizado en una de las más arteras y autoengañosas evasiones de la naturaleza humana con respecto de las responsabilidades morales de la cultura política liberal. A la luz de la historia que he discutido, debe ser una preocupación central de los presentes gobiernos constitucionales elaborar nuevas formas de principios constitucionales que reconozcan y remedien las corruptibilidades del poder político, incluyendo el poder político democrático, a la luz de la razón política. Si el gobierno constitucional es, como observó Madison, la más grande de las reflexiones de la naturaleza humana en la política, los constitucionalistas de hoy deben reflexionar sobre lo que hemos aprendido de la experiencia acerca de las consecuencias de nuestros errores de principio y nuestras responsabilidades para construir, elaborar e imponer doctrinas de igual protección adecuadas a nuestras necesidades morales y políticas.

Tanto los Estados Unidos como Europa ilustran las malignas consecuencias de un compromiso inestable y falto de fundamento con los derechos humanos como base en principio de la unidad nacional. Una base irrazonable para la unidad nacional es buscada en una ortodoxia cultural dominante, y las dudas razonables sobre dicha ortodoxia son resueltas mediante la supresión de las culturas diferentes y mediante los intentos irracionalistas de imponer falsas certidumbres que hacen de las culturas diferentes de la ortodoxia una base natural para la exclusión de la comunidad política. El argumento en favor de la tolerancia empieza con la desconfianza hacia las apelaciones a las estructuras naturales de autoridad que frustran los poderes morales de autogobierno de la gente; el argumento exige hoy, como cuestión de principio, una continua preocupación por la impactante forma moderna de ese mal político, el racismo, que surge, como el genio mato de la sinrazón, en reacción contra lo que parecen ser las más grandes victorias de la razón política. 